\title{
Pedro Lessa e sua influência na evolução constitucional do Brasil
}

\author{
Rubem Nogueira \\ Catedrático na Faculdade Católica de Direito \\ da Bahia.
}

A reconstituição histórica do pensamento filosófico que um dia agitou a vida da Faculdade de Direito de São Paulo, levou um dos seus mais distintos livres-docentes, a doutora Ester de Figueiredo Ferraz, a, estudando a obra do nosso incomparável processualista - João Mendes Júnior — considerá-lo o maior filósofo que até hoje passou pelas Arcadas. ${ }^{1}$

A própria pesquisadora, entretanto, adiante dá o exato sentido ềm que como tal considera João Mendes Júnior.

No rigor da concepção, êle não terá sido um filósofo, mas "um homem que sabe, que conhece profundamente filosofia", e "possui a maior e a mais sólida cultura filosófica de sua época em nossa terra". Filiado à doutrina aristotélico-tomista, "limitou-se a estudar os sistemas filosóficos já elaborados, sem procurar desenvolver qualquer esfôrço pessoal visando atingir a essência, fundamento e condições lógicas de evolução do fato jurídico".

Em suma, diz a brilhante professôra paulista de Direito Penal, “João Mendes Júnior é precìpuamente um jurista", cujo pensamento filosófico, não é muito grato ao ambiente acadêmico daquela época, não conseguiu exercer nos estudantes tão generalizada e forte atração quanto o de Pedro Lessa.

(1) Cfr. "A Orientação Filosófica de João Mendes Júnior", in Ensaios de Filosofia do Direito, São Paulo, 1952, p. 13-55. 
Estudando, em lúcido ensaio, a obra e a vida de João Mendes Júnior, afirma o notável processualista Prof. Alfredo Buzaid que êle fêz uma aplicação da filosofia aristotélico-tomista d̀ ciência do processo, tendo consistido "a sua contribuição original em elaborar, entre nós, uma filosofia do direito judiciário. ${ }^{2}$

Pedro Augusto Carneiro Lessa, mineiro de origem, doutourou-se em direito na Faculdade Paulista em 1884, e já em 1891, depois de três anos de experiência letiva como professor substituto, era alçado à difícil cátedra de Filosofia do Direito. Acêrca de suas qualidades de educador universitário, escreve sóbrio historiador dos fastos da Academia: "Professor insigne, de uma cultura profunda, foi, verdadeiramente, o criador da cadeira de filosofia do direito, nos nossos cursos jurídicos". ${ }^{3}$ Aí está ainda dito que êle era dos professôres mais acatados pelos moços.

Êsse traço da sua individualidade lhe é também assinalado por Antônio Gontijo de Carvalho, em recente e admirável trabalho crítico e biográfico acêrca do chanceler Raul Fernandes. ${ }^{4}$

Traçando o perfil dos lentes do tempo de Raul Fernandes acadêmico, (1895-1898), quando ainda dirigia a vetusta Academia do distrito de Piratininga a veneranda autoridade do já então nonagenário processualista Barão de Ramalho, Gontijo de Carvalho, no seu agradável e bem feito livro, cita em primeiro lugar Pedro Lessa, de quem afirma ter sido o renovador do pensamento filosófico da Academia, o de maior influência no espírito dos moços,

(2) Alfredo Buzaid, "João Mendes de Almeida Júnior, aspectos de uma grande vida", S. Paulo, p. 81 e 83.

(3) Waldemar Ferreira, "A Congregação da Faculdade de Direito de São Paulo na Centúria de 1827 a 1927”, S. Paulo, 1928, p. 81-2.

(4) "Raul Fernandes, um servidor do Brasil", Agir Editora, Rio, 1956. 
entre aquêles "vultos que a perspectiva do tempo engrandeceu". 5

De sua posição filosófica deixou-nos o monumento capital nos ensaios que publicou na Revista da Faculdade de Direito, os quais eram desenvolvimentos de seu programa professoral e que posteriormente compuseram os sete extensos capítulos de seu livro "Estudos de Filosofia do Direito" (notadamente o quarto capítulo, sôbre o determinismo psíquico e a imputabilidade e responsabilidade criminais, que só êle daria um livro autônomo com as suas quase duzentas páginas de texto).

Às idéias evolucionistas e empíricas que preponderavam na época do seu magistério superior, deu-lhes Pedro Lessa grande relêvo e certo cunho de atualidade, conforme o insuspeito depoimento de seu atual sucessor na cadeira, o professor Miguel Reale, no capítulo XII do $2 .^{\circ}$ volume de sua apreciada Filosofia do Direito, ${ }^{6}$ onde dedica algumas páginas à posição filosófica de Pedro Lessa.

Para isso há-de ter contribuído a linguagem de que se servia o autor. Analisando embora problemas científicos, cujo tratamento não pode simplificar-se ao extremo de ser por todos entendido, pois a ciência, e principalmente a filosofia, que é a ciência retora, tem a sua nomenclatura específica, só acessivel aos iniciados; Pedro Lessa expri= mia-se com uma nitidez vocabular muito capaz de torná-lo fàcilmente compreendido e, pois, admirado.

Graças talvez a êsse estilo que tanto lhe clarificava as idéias - coisa aliás pouco frequente entre juristas e filosofantes, alguns dos quais não raro dissimulam na linguagem impenetrável ou confusa uma tal ou qual deficiência de assimilação de idéias — é que Pedro Lessa chegou à Academia Brasileira de Letras, onde sucedeu a outro juiz, o ministro Lúcio de Mendonça, e teve o ensejo de pronunciar memoráveis orações, como, por exemplo, a de recep-

(5) Ob. cit., p. 47.

(6) S. Paulo, 1953, vol. I, Tomo II, p. 291-294. 
ção a Alfredo Pujol, seu antigo colega de lides forenses, pois Pedro Lessa, antes de se tornar magistrado, frequentou os auditórios em S. Paulo, como advogado militante. ${ }^{7}$

\section{Um homem combativo}

Advogado, escritor, professor, juiz. Só a política não conseguiu seduzi-lo. Votava-lhe certa ogeriza, diante, é claro, do espetáculo brasileiro. Falando em 1906 como paraninfo da turma de bacharelandos da Faculdade paulista, assinalou a mediocridade da nossa política, principalmente por causa de incapacidade do elemento humano de que ela se nutria.

"É que, senhores, - dizia êle - com exceções tanto mais nobilitantes, quanto mais raras se vão tornando, os políticos brasileiros se distinguem especialmente, porque timbram em não conhecer os mais indispensáveis preparatórios para o exercício das suas árduas e nobres funções: a história, a sociologia, a moral, o direito, a economia política. Já os encargos de legislar e executar as leis são conferidos, nâo aos que deram prova de maior capacidade, mas por uma espécie de seleção inversa, em que a mais condenável abdicação do povo, a mais egoística e indecorosa suspeita dos governos e as mesquinhas emulações dos políticos profissionais, geram em regra a vitória dos menos idôneos intelectual e moralmente. ${ }^{8} \mathrm{E}$ adiante assim falou ainda, como se estivesse vivendo em 1959: "Hoje, quando no seio de uma família numerosa há um jovem que, por falta de certa vivacidade de espírito e de outros predicados naturais, ou dos que se adquirem pelo esfôrço e pelo trabalho, não pode grangear os meios de subsistência, e

(7) Cfr. "Academia Brasileira de Letras", Sessão solene em 23 de julho de 1919. Discurso de Recepção do sr. Alfredo Pujol. Discurso em resposta pelo sr. Pedro Lessa, S. Paulo, MCMxix.

(8) Pedro Lessa, "Discursos e Conferências", Rio, 1916, p. 54-5. 
menos ainda obter qualquer colocação saliente; ou um ancião vencido da vida, para quem a fortuna foi descaroável madrasta nas profissões que tentou, sem disposição alguma para o exercício de qualquer mister conhecido e lícito; dá-se não raro uma espontânea conspiração entre os conjuntos por parentesco de um ou outro, os políticos militantes e os detentores do poder, para elevar o inclassificável às várias posições políticas, e então, com o mais bemaventurado júbilo dos chefes das agremiações assim enriquecidas, êsse vai a ser legislador, êsse vai ser estadista"...

A aquarela é irrepreensivel. Dá a imagem acesa do Brasil-político de ontem e também ainda do de hoje. Era natural que uma política em tais moldes não seduzisse uma estrutura de eleição como a de Pedro Lessa, sem embargo do seu feitio pessoal ardente e até mesmo impetuoso. Certa feita, dois anos antes de ingressar na magistratura, inconformado com a desordem reinante no ensino e para a qual, segundo Aureliano Leite, êle queria chamar a atenção dos poderes públicos, aprova com distinção a unanimidade de seus alunos de Filosofia do Direito! 9

No debate era igualmente arrebatado. Experimentoulhe a maneira peculiar de discutir assuntos científicos, o seu provecto colega João Mendes Júnior, quando ambos disputaram em tôrno da competência de legislar, no Brasil daquela época, sôbre matéria de processo, em face do que dispunha o texto da Constituição de 1891. Na interpretação dêsse texto, chegaram um e outro a entendimento radicalmente contrário, pois enquanto João Mendes Júnior afirmava a unidade do direito adjetivo ou processual, como uma decorrência da exegese constitucional, Pedro Lessa só aceitava essa unidade em direito constituendo. Em face do direito positivo brasileiro, sufragava a tese de

(9) Cfr. Aureliano Leite, "História da Civilização Paulista", Edição Monumental Comemorativa do IV Centenário da Cidade de São Paulo, Ed. Saraiva, S. Paulo, 1954, p. 266. 
que aos Estados é que era explìcitamente permitido legislar sôbre o processo das justiças locais. ${ }^{10}$

A controvérsia extravasou do assunto específico, graças ao temperamento um tanto ardoroso de Pedro Lessa, que atacou inclusive a posição filosófica do seu velho colega e lhe estigmatizou o método escolástico, bem como o estudo que fêz das noções de substância e acidentes, matéria e forma, essência e existência, potência e ato, - estudo por Pedro Lessa desdenhado mas hoje tido como exaustivo e profundamente filosófico. ${ }^{11}$

Aí, nessa polêmica que fêz época, o estilo refletia corretamente o homem combativo que por índole sempre foi, ao ponto de raiar mesmo talvez por um certo quê de intolerância contra opiniões adversas, segundo registra o seu grande admirador Levi Carneiro, em artigo escrito após a sua morte. ${ }^{12}$

\section{Poderosa estrutura de magistrado}

A cena por excelência de sua atividade, entretanto, foi a cena judiciária - no papel de juiz, que êle assumiu já na plena madureza dos 48 anos de idade. Para desempenhar êsse papel trouxe a visão ampla, geral e penetrante do advogado, suas técnicas inconfundíveis de tratamento dos temas, técnicas cuja falta é tão perceptível entre os magistrados que não tiveram a insuprível experiência da advocacia militante. Trouxe ainda a visão profunda do fenômeno jurídico, o domínio completo da ciência dos princípios, que a filosofia, e só ela, pode fornecer. Sem ela - disse-o êle próprio, "a tarefa do jurista se reduz a

(10) Cfr. Pedro Lessa, "Dissertações e Polêmicas”, Rio, 1909, p. $233-279$.

(11) Cfr. Ester de Figueiredo Ferraz, "Ensaios de Filosofia do Direito", cit., p. 15.

(12) Cfr. Levi Carneiro, "O Livro de Um Advogado", Rio 1943, p. $43-5$. 
um esfôrço inferior por interpretar e aplicar preceitos, de cujo verdadeiro e profundo sentido não the é dado compenetrar-se". (Prefácio da $1 .^{a}$ edição de seus "Estudos de Filosofia do Direito"). Trouxe finalmente a queda pelo debate, o gôsto de enfrentar os temas de mais nítido caráter polêmico, cujo discernimento sua cultura básica estava sempre apta a elaborar.

Dando-lhe uma cadeira perpétua de juiz, aos 26 de outubro de 1907, em sucessão a Lúcio de Mendonça, o Presidente Afonso Pena possivelmente terá tido a consciência de que abria as portas do Supremo Tribunal Federal ao que seria, até 1921, quando desapareceu, o seu maior juiz.

Não tendo antes jamais vestido a toga, começou pelo fim da carreira judiciária, mas revelou-se, não obstante, um juiz de primeira grandeza, em treze anos de constante judicatura; constante e produtiva. Ao interromper a tarefa de todos os dias - conta Levi Carneiro - estava irremediàvelmente exausto, relacionando-se ao esfôrço que lhe custou a sua obra judiciária a vida relativamente breve que teve, pois morreu com apenas sessenta anos de idade.

A jurisprudência brasileira especialmente no campo do direito constitucional, recebeu de Pedro Lessa contribuição decisiva, que lhe inaugura uma etapa digna de registro.

Foi no seu tempo, e enquanto publicista, talvez mais influente do que, no campo do direito privado, é presentemente Orozimbo Nonato, ou eram, ha dez anos, Filadelfo Azevedo e Castro Nunes nos campos de suas mais acentuadas especializações.

\section{Ruy e Lessa, duas influências gêmeas}

Estudando a nossa organização democrática e o problema das liberdades civis, no segundo volume de "Instituições Politicas Brasileiras", chega Oliveira Viana à conclusão de que as liberdades civis do povo-massa do Brasil não sossobraram completamente em consequência da des- 
centralização política implantada com o regime republicano, ùnicamente por causa da aplicação extensiva do habeas-corpus, de sua ampliação providencial, inspirada na doutrina de Ruy Barbosa e na jurisprudência do Supremo, sem embargo daquilo que o laureado sociólogo patrício considera a "exegese estrita de Pedro Lessa". ${ }^{12 a}$

Pedro Lessa e Ruy Barbosa, entretanto, se completam na influência incomparável que ambos exerceram na construção jurisprudencial responsável pela chamada teoria brasileira do habeas-corpus, que predominou até 1926 e veio a determinar o advento dessa formidável conquista do nosso direito positivo atual que é o Mandado de Segurança.

O desenvolvimento dessa influência assumiu proporções monumentais no esfôrço de ambos, no sentido de tornar o habeas-corpus o recurso capaz de invalidar os atos do poder público não apenas cerceadores da simples liberdade de ir e vir, mas que criassem qualquer violência ou coação ao indivíduo, interceptando-lhe, em consequência, o exercício de um direito seu. Qualquer que fôsse êsse direito, queria Ruy. Inclusive direitos políticos. Foi árdua a batalha para superar a exceção de incompetência do Supremo Tribunal Federal no reexame, mediante habeas-corpus, de matéria política.

Desde 1892, entretanto, já Ruy distinguia entre atos meramente políticos (não controláveis judicialmente) e os que, embora resultantes de funções políticas, envolvem direitos constitucionais do indivíduo, sujeitando-se, assim, à competência revisora dos tribunais. Em suma, proclamava êle que a feição política do ato não furta à ação da justiça os abusos do poder.

Pedro Lessa também aceitava a exceção de incompetência quanto aos casos meramente políticos, mas, integrado quanto a isto no pensamento de Ruy, admitia o contrôle judicial do ato político, desde que êste implicasse

(12a) Ob. cit., p. 231. 
lesâo de um direito individual. O Supremo l'ribunal, para êle, era um Tribunal político, pois podia decretar a inconstitucionalidade de atos dos Poderes políticos. Todos os fatos políticos sujeitos a normas legais, dizia, podem ser discutidos e apreciados pelo Tribunal. ${ }^{13}$

Por isso mesmo Pedro Lessa sempre concedeu habeascorpus para proteger direitos individuais em pleno estado de sítio e ainda mediante o habeas-corpus admitia o reexame da constitucionalidade do próprio estado de sítio, afim de verificar se a sua decretação tinha observado os pressupostos constitucionais - matéria esta por êle mesmo considerada política.

Essa doutrina de Ruy, que Pedro Lessa corajosamente adotou nos seus grandes votos, acabou influindo no novo direito positivo brasileiro.

A Constituição de 46 declara, com efeito, que o sítio não suspende tôdas as garantias, e a inobservância de qualquer das normas reguladoras dêle importará na ilegalidade da coação e dará ao paciente $o$ direito de recorrer aos Tribunais. (Art. 215)

Pedro Lessa queria que a liberdade de locomoção funcionasse como um pressuposto do exercício do direito ilegalmente cerceado ou ameaçado, para então aplicar-seIhe o remédio do habeas- corpus. ${ }^{14}$

No caso da Mesa da Assembléia Legislativa do Estado do Rio, julgado a 6 de junho de 1914 (H. c. n. ${ }^{\circ} 3.554$ ), ficou isso patente. Os deputados João Antônio de Oliveira Guimarães, Raul de Almeida Rego e Constâncio José Mourenat, seu presidente e secretários, em presença da convocação extraordinária àa Assembléia pelo Presidente do E tado, consideraram-se ameaçados no seu direito de exercer aquêles cargos, pelo propósito, que a outra facção

(13) Cfr. Voto no H. c. n.o 3.556, impetrado por J. E. Macedo Soares, Rev. do Sup. Trib. Fed., vol. II, Parte 1. ${ }^{\text {a }, ~ a g . ~ a ~ d e z . ~ d e ~ 1914, ~}$ p. 80 . p. 31 .

(14) Cfr. Arnold Wald, "O Mandado de Segurança", Rio, 1955, $6-2^{\circ}-$ F. D. 
anunciava, de eleger nova Mesa sòmente para o periodo da convocação.

O Supremo Tribunal Federal, contra os votos apenas dos ministros Godofredo Cunha e Coelho e Campos, concedeu a ordem impetrada pelo advogado Astolfo Rezende, para que os pacientes pudessem locomover-se livremente, penetrassem no edifício da Assembléia Legislativa $e$ aí exercessem, livres de constrangimento, durante o período da sessão extraordinária e enquanto ela durasse, as funcões que tinham na Mesa.

Pedro Lessa subscreveu o acórdão, dando, então, como inicialmente frizou, um voto idênticn ao que sempre vinha dando em casos iguais.

Essa maneira sua de encarar o problema conciliarse-ia, em última análise, com a de Ruy. E não é por outra razão que Arnold Wald, estudando exaustivamente êsse assunto em monografia ha pouco editada, assinala que a jurisprudência, no particular da aplicação extensiva do habeas-corpus, adotou a lição de Pedro Lessa, inspirada em Ruy Barbosa. ${ }^{15}$

De fato, segundo a doutrina que Ruy sustentou sempre, a. partir de abril de 1892, o habeas-corpus era o remédio aplicável "a todos os casos onde houver coação ilegal ao indivíduo, onde a personalidade humana, em qualquer das manifestações exteriores da liberdade, se achar violentada por uma invasão do poder".

Quando êle assim se exprimiu, estava em causa a liberdade de circulação de certo jornal gaúcho. Mas, uma vez que o texto constitucional não restringia, antes ampliava a concessão do habeas-corpus a todos os casos de violência ou coação por arbítrio da autoridade, cumpria adotar o instituto segundo a amplitude do art. $72, \S 22$, da Carta Magna. ${ }^{16}$

(15) Cfr. Arnold Wald, "O Mandado de Segurança". Ed. do Serviço de Documentação do DASP, Rio, 1955, p. 36.

(16) Cfr. Ruy Barbosa, artigo "O Habeas-Corpus e a Imprensa", no Jornal do Brasil de 15-8-1893, Obras Completas, vol. xx, Tomo IV, “A Ditadura de 1893", Rio, 1949, p. 137-143. 
Em verdade, o constituinte de 1891 não limitou o conceito de coação ou violência, de sorte que a interpretação ampliativa de Ruy era legítima, e acabou triunfante, embora não correspondesse à concepção ortodoxa, anglosaxônica, do habeas-corpus. Segundo Ruy, tôda pressão empregada "em condições de eficácia, contra a liberdade no exercício de um direito qualquer que êle fôsse”, só poderia ser eliminada pelo habeas-corpus. Falando em 1915 no Senado, explicou bem: "Desde que no exercício de um direito meu, qualquer que êle fôr, intervém uma coação externa, sob cuja pressão eu me sinto embaraçado ou tolhido para usar êsse direito, na liberdade plena de seu exercício, estou debaixo daquilo que, em direito, se considera coação. E violência? Violência é o uso da fôrça material ou oficial, debaixo de qualquer das duas formas, em grau eficiente para evitar, contrariar ou dominar o exercício de um direito" 17

Pedro Lessa queria que o direito fôsse líquido e certo (certeza e liquidez que a nosso ver a doutrina de Ruy essencialmente não dispensa), sob pena de escapar ao contencioso de legalidade do habeas-corpus. Mas, embora ressalvando que êste remédio protegia apenas a liberdade individual no sentido estrito de liberdade de locomoção, sempre o concedeu quando o direito incontestável do paciente, para ser exercido, precisava da garantia daquela liberdade de ir e vir.

Os deputados componentes da Mesa da Assembléia Fluminense não se queixavam pròpriamente de ameaça à sua liberdade de entrada e saída no edifício da Assembléia, senão que temiam não lhes ser possivel exercer as suas funções, porque os seus colegas, solidários com os propósitos políticos do Presidente do Estado, pretendiam eleger outra Mesa, e por isso os impetrante queriam habeas-

(17) Discurso de 22-1-15, in "Comentários à Constituição Federal Brasileira", coligados e ordenados por Homero Pires, vol. V. Rio, 1934, p. 505-6. 
corpus para entrar sem coação no edifício da Assembléia Legislativa e lá exercerem as funções dos seus cargos.

Pedro Lessa não concedeu a ordem apenas para que se lhes garantisse o livre acesso à Assembléia Legislativa (o que estaria mais conforme com a idéia de destinar-se o habeas-corpus ùnicamente à proteção da liberdade de locomoção), mas ainda para que na Assembléia o Presidente e os dois Secretários desempenhassem as suas funções. ${ }^{18}$ Nesta parte de seu voto êle afinava com a doutrina de Ruy.

Teòricamente, ou melhor, no corpo dos seus silogismos jurídicos, Pedro Lessa encarava o habeas-corpus segundo o conceito tradicional, ao passo que Ruy inovou, ou antes, coerente com o texto Constitucional que regulava o instituto, advogou-lhe aquela aplicação ampliativa a que Oliveira Viana ligou, como vimos, a própria sorte das liberdades civis e políticas do nosso povo-massa.

Nas suas consequências práticas, entretanto, talvez as duas concepções - a de Ruy e a de Pedro Lessa — se tenham equivalido.

Haja visto o habeas-corpus que Ruy impetrou para assegurar a publicação dos seus próprios discursos parlamentares pela imprensa, onde, quando e como lhe conviesse. Como se sabe, o Marechal Hermes, já no último ano de seu govêrno, havia decretado a prorrogação do sítio para durar todo o tempo da sessão anual do Congresso. Ruy Barbosa, logo no dia da instalação dos trabalhos do Senado (4 de maio de 1914) discursou protestando contra o absurdo decreto executivo e forneceu cópia datilográfica do discurso ao Imparcial, dirigido por Macedo Soares. O Chefe de Polícia porém proibiu-lhe a publicação. Contra êsse ato governamental Ruy impetrou uma ordem de habeas-corpus, que recebeu o n. $^{\circ} 3.536 \mathrm{e}$ ao ser julgada deu até motivo a um incidente.

É que, feito o relatório, o Ministro Oliveira Ribeiro pediu fôsse dada a palavra a Ruy, cuja inicial êle acabava

(18) Cfr. Revista do Sup. Trib. Fed, vol. II, Parte Primeira, Ag. a dez., 1914, Rio, p. 56. 
de receber, afim de o paciente e impetrante dar esclarecimentos que pudessem "desenvolver o objeto da matéria da petição".

O Presidente, Ministro Hermínio do Espîrito Santo, concedeu a palavra ao paciente e impetrante, mas pelo -xíguo prazo do Regimento. O Relator, falando pela ordem, fêz ver que o caso era especial, não previsto no invocado dispositivo regimental que reduzia a 15 minutos o tempo de sustentação oral, pois iria ouvir-se o próprio paciente. O Ministro Presidente rendeu-se à evidência, e Ruy ocupou a tribuna por mais de uma hora, atacando, porém, duramente a intervenção presidencial que pretendeu bitolar-lhe o direito de defesa oral. (Êsse incidente parece revelar que Levi Carneiro não tem razão quando atribui a Pedro Lessa a iniciativa de se conceder, no Supremo Tribunal Federal, a Ruy Barbosa o privilégio de falar sem limitação de tempo. E o próprio Ruy, no discurso acima referido, quem afirma jamais lhe haverem no Supremo tentado "medir o uso da palavra com o correr da areia na ampulheta").

Da tribuna traçou então Ruy a luminosa interpretação dos textos constitucionais atinentes ao sítio, patenteando a irremediável inconstitucionalidade do sítio e do cerceamento posto pela Polícia à divulgação ampla das opiniões, palavras, votos e discursos dos parlamentares. Esse improviso, que ocupa vinte e cinco páginas da Revista onde se estampou, é um dos instantes mais belos e grandiosos da eloquência forense do seu autor. ${ }^{19}$

$O$ relator concede a ordem, para ficar ao impetrante assegurado (a expressão usada no seu voto é exatamente essa) o seu direito constitucional de publicar os seus discursos parlamentares, pela imprensa, "onde, quando e como lhe conviesse".

Pedro Lessa vota logo depois da impugnação do pedido pelo ministro Muniz Barreto, Procurador Geral da

(19) Cfr. Rev. do Sup. Trib. Fed., abril a julho de 1944, vol. I, Primeira Parte, Rio, 1914, p. 260-285. 
República. Acolhe a tese de Ruy quanto à inconstitucionalidade do decreto executivo que prescrevera o sítio, visto não haverem ocorrido os seus pressupostos (guerra ou comoção intestina), e cita o próprio Ruy, assim: "Como muito bem disse o Senador Ruy Barbosa, a comoção intestina, o iminente perigo que corre a pátria, deve ser alguma coisa que, pela sua gravidade, seja comparável à guerra internacional"

E também concede a ordem, sem nenhuma discrepância da extensão que lhe dera o Relator, contra cuja opinião fica solitário o ministro Godofredo Cunha.

Certo é que, na sustentação de seu voto, Pedro Lessa, ao estender a ordem não só a Ruy, senão a todos os jornalistas do Imparcial, admitia haver no caso uma coação, isto é, dizia êle, "se os jornalistas publicassem os discursos, seriam presos, como já o foram alguns por outras publicações". E concluía êste seu raciocínio: "Por conseguinte, pode se ter certeza de que, se não fôr concedido habeas-corpus, os jornalistas que publicarem os discursos serão coagidos em sua liberdade individual"

Mas, a rigor, o direito de locomoção não funcionava aí como um pressuposto do exercício do direito de publicar discurso. Contudo, Pedro Lessa concedeu a ordem impetrada, sem que a liberdade individual de locomoção estivesse principalmenie ameaçada, ou exprimisse, na espécie, aquilo que êle denominava o direito escôpo. O "direito escôpo", aí, resultava da imunidade assegurada no art. 19 da Carta de 91 e que o sítio não podia interceptar. (Sôbre o direito escôpo falou Pedro Lessa em voto vencido no habeas-corpus $\mathrm{n}^{\circ} 3.539$, que Ruy requereu em favor dos diretores e redatores do Imparcial, Correio da Manhã, A Noite, Gazeta e a A Época, e foi negado pelo Supremo. ${ }^{20}$

Pedro Lessa, portanto, em última análise não se distanciou de Ruy na concepção prática do habeas-corpus e

(20) Cfr. "Rev. do Sup. Trib. Fed.", ano de 1914, ag. a dez., vol. II, Primeira Parte, p. 294. 
seu raio de alcance. Coerente com a sua posição doutrinária em face dêsse problema jurídico, votou pelo deferimento de todos os habeas-corpus que Ruy impetrou para a defesa de direitos políticos (exercício de funções governamentais e legislativas), quando ocorreram na Bahia, em 1912, os tristes episódios que culminaram no bombardeio de sua Capital. ${ }^{21}$

A jurisprudência, até 1926, sufragou, inclusive çom o voto de Pedro Lessa, o conceito amplo dêsse remedium juris, que tão luminosamente assinala a presença de Ruy Barbosa na história da civilização política e jurídica de nossa Pátria.

Em 5 de maio de 1919, quando Ruy, pelo seu patrono, dr. Artur Pinto da Rocha, requereu uma ordem de habeas-corpus para si e para Miguel Calmon, Pedro Lago, Simões Filho, Medeiros Neto, Vital Soares, Lemos Brito, Pires de Carvalho, Altamirando Requião, Otaviano Sabach, Américo Barreto, Porto da Silveira, Agenor Chaves, Madureira de Pinho, Mário Leal, Homero Pires, João Mangabeira, Arquimedes Pires, Alfredo Rui e Caio Monteiro de Barros - para fazerem comícios na Bahia e especialmente na Cidade do Salvador, comícios que o Chefe de Polícia Alvaro Cova tinha proibido, o Supremo Tribunal concedeu a ordem por unanimidade. ${ }^{22} \mathrm{E}$ no acórdão respectivo está dito precisamente: "Com efeito, para a maioria do Tribunal, é principio corrente que o habeas-corpus é competente para proteger o exercício de qualquer direito, desde que êste seja certo, líquido e incontestável" - premissa esta que se continha no pensamento tanto de Ruy Barbosa quanto de Pedro Lessa.

Quando, por conseguinte, a reforma constitucional de 1926 reduziu a concessão do habeas-corpus aos casos de ofensa à liberdade física de ir e vir - sob o pretexto irrisório de restaurar o sentido ortodoxo dêsse instituto

(21) Cfr. "Obras Completas de Rui Barbosa", vol. XxxIX, 1912, Tomo I, O caso da Bahia, Rio, 1950.

(22) Cfr. "Revista de Direito", vol. 64/288. 
ou de coibir supostos exageros da construção jurisprudencial amplativa que vinha ao encontro de uma grave lacuna do nosso direito formal, a saber, a falta de um remédio jurídico para a pronta e eficaz defesa dos direitos individuais violados ou ameaçados de violação por atos ilegais dos agentes do Poder Público, - quando os constituintes de 1926 assim procederam, contrariaram tanto o ideal do habeas-corpus de Ruy Barbosa quanto o de Pedro Lessa.

Ambos êles tinham, porém, impregnado de tal forma a consciência jurídica brasileira de inviolabilidade dos direitos individuais constitucionalmente consagrados e tão firmemente a jurisprudência do Supremo Tribunal Federal thes tinha apoiado a doutrina da aplicação extensiva do habeas-corpus, que o legislador não descansou até que o direito positivo brasileiro preencheu o clamoroso espaço vasio deixado pela reforma constitucional do Govêrno Bernardes e introduziu no sistema de defesa dos direitos individuais o remédio do mandado de segurança.

Seus mais legítimos precursores são, pois, inegàvelmente, Pedro Lessa e Ruy Barbosa.

Para Pedro Lessa a liberdade de locomoção "é um meio para a consecução de um fim, ou de uma multiplicidade infinita de fins", e, como acertadamente observa Arnold Wald, hoje diríamos mandado de segurança, onde aquêle grande juiz, nalguns dos seus votos principais, cogita de habeas-corpus. ${ }^{23}$

Ruy Barbosa com a sua luta sem quartel pelos interditos clássicos na proteção dos direitos pessoais e reivindicando a cobertura do habeas-corpus para proteger o exercício de todo e qualquer direito individual contra os transbordamentos tìpicamente brasileiros do Poder Executivo, encontrou em Pedro Lessa o juiz bravo, culto e honesto, em condições, portanto, de demandar a construção jurisprudencial que tanto serviu ao povo brasileiro. Juiz bravo, sim, como a história atesta. No julgamento do habeas-corpus 3.539 que Ruy impetrou a benefício dos

(23) Cfr. Arnold Wald, ob. cit., p. 33. 
diretores e redatores do Correio da Manhã, Imparcial e outros jornais do Rio, e que o Supremo indeferiu sob o fundamento de haver sido suspensa pelo estado de sítio a garantia constitucional da livre manifestação do pensamento, Pedro Lessa assinou o acórdão vencido, em tudo (textual), e a certa altura de seu voto classifica de caprichoso, arbitrário, criminoso o ato do Marechal Hermes da Fonseca que decretara o sítio "violando um claro preceito da Constituição e innicamente para a satisfação de ódios $e$ vinganças pessoais".

Nas lições de Ruy e Pedro Lessa é que entre nós se foi buscar a mais decisiva inspiração para elaborar o novo instituto de defesa enérgica e eficaz dos direitos do indivíduo não amparados pelo habeas-corpus.

Os abusos da Autoridade Pública voltam a encontrar no sistema jurídico brasileiro um veto fulminante, através do mandado de segurança, cujas formas embrionárias e perfeitas os trabalhos de Ruy e os votos lapidares de Pedro Lessa já sugeriam à posteridade. 